International Journal of Child, Youth and Family Studies (2014) 5(2): 308-331

\title{
TURNING POINTS AND TRANSITIONS: THE ROLE OF FAMILY IN WOMEN'S IMMIGRATION EXPERIENCES
}

\author{
Colleen K. Vesely, Rachael D. Goodman, and Shannon Scurlock
}

\begin{abstract}
Given the significant number of immigrants in the United States, especially immigrant families with young children, there is a need to better understand the experiences of immigrant women, and especially immigrant mothers. In particular, the factors impacting women's decisions to migrate, migration journeys, and post-migration adjustment should be examined. Framed in family life course theory and using ethnographic, in-depth interviews, we explored these three immigration phases for 40 first-generation Latina and African immigrant women who experienced motherhood in the U.S. Results of the study expand the literature focused on immigration experiences by considering turning points and transitions in women's migration processes, as they are shaped by both micro- (family) and macro- (socio-historical) level factors. The findings illustrate the spontaneous nature of some decisions to migrate, as well as how immigration journeys are influenced by the financial and physical supports of families and the status of their documentation. In addition, study findings point to motherhood as an important turning point for first-generation immigrant women in their adjustment to life in the U.S., and particularly in their planning with respect to staying long term. Implications for programs, policy, and future research are discussed.
\end{abstract}

Keywords: immigrant women, life course theory, immigration, qualitative research

Colleen K. Vesely, Ph.D. (the corresponding author) is an Assistant Professor of Early Childhood Education, Human Development and Family Science in the College of Education and Human Development at George Mason University, Fairfax Campus, Thompson Hall 1102, MS 4C2, 4400 University Drive, Fairfax, Virginia, USA 22030. Telephone: (703) 993-5346. E-mail: cvesely@gmu.edu

Rachael D. Goodman, Ph.D., LPC is an Assistant Professor in Counseling and Development in the College of Education and Human Development at George Mason University, Fairfax Campus, Krug Hall 201 C, MS 1H1, 4400 University Drive, Fairfax, Virginia, USA 22030. Telephone: (703) 993-5242. E-mail: rgoodma2@gmu.edu

Shannon Scurlock, MA, is a graduate of the Applied Developmental Psychology program at George Mason University and is a Behavior Therapist in Northern Virginia.

Telephone: (856) 305-5274. E-mail: sscurloc@gmu.edu 
International Journal of Child, Youth and Family Studies (2014) 5(2): 308-331

Just over half (51\%) of the approximately 40 million immigrants in the United States are women (Britz \& Batalova, 2013). Immigrants make up 13\% of the U.S. population, and it is predicted that the foreign-born population will be 19\% of the population by 2050 (Passel \& Cohn, 2008; U.S. Census Bureau, 2013). Given the growing immigrant population, it is necessary to better understand the dynamics of the immigrant experience, from the decision to migrate through adjustment to the U.S. Research indicates that a number of factors shape immigrants' experiences at various turning points throughout the migration process. In particular, push and pull factors often influence individuals' reasons for migrating and experiences post-migration (Alk et al., 2007; Goldin, Cameron, \& Balarajan, 2011); these factors include economic stability in the country of origin and the new host culture, language ability, the

presence of ethnic enclaves, documentation status, social support, immigration and social service policies, and cultural identity and acculturation (Chen, Benet-Martinez, \& Bond, 2008; Portes \& Rumbaut, 2006; Settles, 2001). Moreover, recent research points to the unique experiences of women in migration (Curran, Shafer, Donato, \& Garip, 2006; Falicov, 2007), as well as the important role of families in immigration decisions and experiences (Bashi, 2007; Glick, 2010).

However, there is very limited literature that has focused specifically on the experiences of immigrant mothers. As such, to develop a comprehensive understanding of women's experiences throughout the migration process, as they become mothers in the U.S., it is critical to utilize a framework that attends to the role of family, as well as the numerous micro- and macrolevel factors that contextualize both individual and familial experiences and processes. In this paper, we draw upon a family life course perspective to understand how micro- or family-level factors, coupled with broader macro-level influences, shape the immigration processes and experiences of first-generation immigrant women who ultimately become mothers in the U.S.

\section{A Family Life Course Understanding of Immigration Experiences}

The term "family" has been broadly defined across history and cultures. When we consider family, particularly among immigrant mothers, it is important to note descriptors such as nuclear and extended family, family of origin, and family of procreation, as well as move beyond notions of what Peters (1999) calls the Standard North American Family (SNAF). In this paper we examine the experiences of Latina and African immigrant mothers, with a broad definition of family and a particular focus on how mothers themselves conceptualize their families, which includes extended family members as well as families mothers were born into (families of origin) and families they created through marriage, partnering, and/or childbearing (families of procreation).

Family life course theory explains the interconnections of family relationships within specific socio-historical and geographic contexts and how these shape an individual's life course. In particular, this theory considers how developmental or chronological age, typical life transitions, relationships with others, and socio-historical change contribute to one's life trajectory (Hutchinson, 2007). Life course theory connects the micro- and macro-levels of individuals' environments through various aspects of time, including components of individual developmental time, family time, and socio-historical time. Given this multi-dimensional focus 
International Journal of Child, Youth and Family Studies (2014) 5(2): 308-331

on time, as well as the relationships within these chronological spaces, life course theory provides a foundation for understanding the complexity of women's migration experiences and related transitions.

Two concepts of life course theory are especially relevant in exploring immigration experiences. First, the concept of linked lives explains the interconnectedness among the lives of individual family members and the historical context, such that the developmental trajectories of family members are interdependent and shaped by each other, as well as social and historical influences (Elder, 1989; Greenfield \& Marks, 2006; Hutchinson, 2007). This idea suggests that women's migration experiences may be influenced by events in their countries of origin and the new host society, as well as their interactions within their most salient family relationships, including parents, children, siblings, and partners. A second theme of life course theory that is particularly important to women's immigration experiences is the notion of interplay of human lives and historical time, or how individuals' lived experiences are shaped by when and where they live throughout their life course (Elder, 1989; Hutchinson, 2007). For the women in this study, their immigration experiences were shaped not only by where they were migrating from and to, but also the climate of immigration in the United States in terms of policies and laws when they migrated.

Life course scholars discuss the role of life events, or changes that may lead to significant effects on the individual and/or family (Settersten, 2003). These life events are followed by transitions (Elder \& Kirkpatrick Johnson, 2003; Hutchinson, 2007), or changes to individuals' roles in their families such as parenthood (Carter \& McGoldrick, 2005). Sometimes these transitions lead to individuals entering and exiting the family through births, deaths, marriages, divorces, and separations (Hutchinson, 2007). Moreover, life course theory gives insight into turning points or those life events that (a) expand or reduce opportunities, (b) bring on a permanent change to an individual's ecology, or (c) change an individual's self-concept (Hutchinson, 2007; Jasso, 2003). Jasso (2003) indicated that migration is one turning point that reflects all three of these aforementioned types of life events.

\section{Immigrant Women and the Migration Process}

As Settles (2001) noted, macro-level forces are interpreted at the micro-level, meaning that immigrant women will experience the impact of the larger socio-historical context individually and within their family systems. Therefore, in addition to utilizing a family life course theoretical perspective to understand immigrant women's experiences, we examine research on a number of salient factors impacting this population throughout the migration process. In particular, to understand immigrant women who are mothers, we highlight scholarship on the role of families and social support, as well as the unique experiences of female immigrants who are parents.

According to Glick (2010), the reasons individuals migrate are often linked to their family systems. Research focused on families and immigration most commonly highlights parenting across the lifespan (Senyurekli \& Detzner, 2008; Treas, 2008), as well as gender and the role of couple relationships in immigration (Cerrutti \& Massey, 2001; Glick, 2010; Perreira, Chapman, \& Stein, 2006). For women who are mothers, the ways in which families influence 
International Journal of Child, Youth and Family Studies (2014) 5(2): 308-331

their migration experiences are likely to vary based on a number of factors throughout the migration and adjustment processes. For example, mothers with adolescent children often migrate for economic prospects, educational opportunities, and safe environments for their children, as well as to reunite with their children’s fathers (Perreira et al., 2006).

Researchers have noted the importance of social support and social networks during migration (e.g., Bankston \& Zhou, 2002; Kao \& Rutherford, 2007; McKether, 2008). Ornelas, Perreira, Beeber, and Maxwell (2009) found that immigrant mothers experiencing stress and other emotional problems used social networks and community resources to promote resilience. The importance of parenting experiences related to migration is apparent later in the life course as well, with parents living transnationally to support their grown children and grandchildren (Treas, 2008). Moreover, adult children and their aging parents work in creative and unique ways to maintain a sense of family across borders and distances of thousands of miles (Senyurekli \& Detzner, 2008).

Further, literature focused on families and immigration examines the role of gender and couple relationships in migration. Often, the migration motivation of a male figure is the primary focus of immigration scholarship, with a female partner seen as a secondary actor who follows a husband or boyfriend to the new host country (Cerrutti \& Massey, 2001; Glick, 2010); this is particularly true in literature on border crossing, which has focused primarily on Latino men (DeLuca, McEwen, \& Keim, 2010; Infante, Idrovo, Sanchez-Dominguez, Vinhas, \& GonzalezVazquez, 2012). However, women have their own considerations and experiences when migrating, particularly when responsible for the care of others (Neufield, Harrison, Stewart, Hughes, \& Spitzer, 2002). The changing global economy has created economic opportunities for women, leading to the "feminization of migration" (Falicov, 2007, p. 160). Research indicates that immigrant women, particularly those from Latin America, tend to utilize their families and family connections as sources of support (Dominguez \& Lubitow, 2008). Women may be selected to migrate to further the family's economic interests because women are considered especially reliable in terms of sending remittances to the family after migration (Goldin et al., 2011). However, there may be power imbalances in women's relationships with male partners that influence women's migration process by prioritizing the male partners' needs (Killian, Olmsted, \& Doyle, 2012; Meares, 2010). Additionally, economic opportunities for women may be lower paid and less stable than those for their male counterparts due to their overrepresentation in domestic and care work (Fitzpatrick, 1997; Henrici, 2013).

Finally, immigrant parents often face unique challenges negotiating the cultural and linguistic differences between their countries of origin and their new environments that emphasize autonomy and English proficiency (Glick, 2010) and have social services and government programs that encourage assimilation into the host society (Settles, 2001). Retaining ethnic identity is often a central concern for parents, and ethnic enclaves and religious institutions can function to support this endeavor. Common challenges faced by immigrant parents include social isolation and disconnection from family, experiences of discrimination, concerns over raising a child in a new environment, navigating unfamiliar social systems, and financial worries (Dominguez \& Lubitow, 2008; Perreira et al., 2006). In addition, parents who are undocumented immigrants face additional institutional and emotional challenges related to accessing supports for themselves and their children, and live in fear of deportation (Yoshikawa, 
International Journal of Child, Youth and Family Studies (2014) 5(2): 308-331

2011). To overcome these challenges, immigrant parents may utilize transnational support by connecting with family members in their countries of origin to obtain emotional support (Dominguez \& Lubitow, 2008). Developing and maintaining transnational family structures in which families connect and interact while in different countries can provide needed support as immigrant parents face the challenges and emotional strains that accompany the migration experience (Falicov, 2007). For example, Perreira et al. (2006) found that immigrant mothers' resilience was connected to developing bicultural coping skills and adapting their parenting skills to their new environment.

While the literature provides an understanding of the multiple factors that might influence immigrant women's experiences, there is a need to further understand how family and family networks shape the entire immigration process and the relevant transitions from the time individuals leave their home country through their experiences adjusting in the new country (Settles, 2001), especially for mothers. Currently, there is limited empirical work to support a theoretical frame focused on the role of families in migration (Bashi, 2007). Consequently, despite our growing understanding of immigrants' experiences and the role of family in these experiences, our understanding of this process over time (individual, family, and sociohistorical), considering both micro- and macro-level factors, among women who are mothers, is limited.

\section{The Current Study}

To generate a comprehensive understanding of the turning points and transitions that female migrants who adjust to being mothers in the U.S. experience, research must include an examination of women's experiences pre-migration, during migration, and post-migration. Without an understanding of all three phases, researchers, policy-makers, and practitioners may fail to address related sources of stress and strength. Furthermore, the understanding of immigrant women should include a comprehensive view of how family influences women, expanding beyond the traditional emphasis on the influence of a male partner (Cerrutti \& Massey, 2001). Theoretical and some empirical work support the importance of family across all three phases of the immigration process; however, the particular family members or family experiences that impact women appear to vary, and this may be especially true of women from various regions of origin (Vesely, 2013). Therefore, the two foci of this study are:

1. Examining how family or micro-level and socio-historical or more macro-level processes shape first-generation immigrant women's transitions to life as mothers in the United States; and

2. Elucidating how mothers' experiences of migration as a significant life event and the transition that follows, in terms of adjusting to, and simultaneously becoming mothers in, the United States, is an important turning point for their adjustment to the new country.

\section{Participants}

\section{Methods}

Participants were 40 first-generation, low-income immigrant women who hailed from various African countries $(n=19)$ and Latin America $(n=21)$. On average, the women had 
International Journal of Child, Youth and Family Studies (2014) 5(2): 308-331

migrated to the U.S. about a decade before they were interviewed for this study and were just over 30 years old at the time of the interview. See Table 1 for additional descriptive demographic data. The majority of Latina mothers in this sample lived in a single neighborhood that was an ethnic enclave within a large urban center on the east coast of the United States. Much of their daily routines could be accomplished in Spanish, with local early childhood education programs, health clinics, and supermarkets offering services in English and Spanish, reflecting the bilingual nature of the neighborhood. However, the majority of African mothers lived in a suburb outside of this large urban center that was home to many different immigrant groups. Access to institutions where African languages and cultures were represented was less common compared to what the Latina mothers experienced in the city.

\section{Data Collection}

A modified grounded theory approach was used to collect and analyze data in this study. This approach allowed for consideration of ideas and theories from prior studies that informed and guided the goals and analyses of this study (Daly, 2007; LaRossa, 2005; Strauss \& Corbin, 1990). Sensitizing concepts or guiding ideas from family life course theory and other concepts in the literature shaped the development of the interview protocol, as well as the earliest phases of data analysis (Van den Hoonard, 1997). In particular, in-depth semi-structured interviews were conducted with participants to understand their lived experiences.

Recruitment. Recruitment efforts commenced after receiving Institutional Review Board (IRB) approval. Inclusion criteria for this study were: (a) having a child who was enrolled in Head Start or another free or reduced fee early childhood education (ECE) program; and (b) being a female, first-generation immigrant. By the time participants were interviewed for this study they were mothers; however, at the time of migrating only eight participants were mothers. Consequently, the experiences of the majority of participants in this study reflect the experiences of women who became mothers at some point during the immigration process and for all women in this study they experienced learning how to mother in the U.S. Participants were purposively sampled (Patton, 1990) for variation in experience including: pre-immigration socio-economic status (education and poverty), legal documentation upon arriving in the U.S., and region of origin. Women were recruited to participate in this study from three ECE programs in a major metropolitan area in the U.S. The first author spent approximately one academic year (nine months) in the field, meeting teachers, children, and parents, and observing in classrooms at the three field sites. All names of individuals and organizations have been changed to protect the privacy of the study participants.

In-depth interviews. There are various estimates of the number of interviews necessary to achieve saturation in qualitative research, or the point at which there is no new conceptual and theoretical information being gleaned from each interview (Daly, 2007), which range from 20 (Daly, 2007) to 30 (Isaac \& Michael, 1981). Because families from diverse regions of origin were recruited, it was necessary to conduct more than 30 interviews such that saturation could be reached within each regional subgroup. Specifically, data were collected from 21 Latin American and 19 African women. Interviewing women ceased when saturation was reached within each of these broad regional ethnic groups. 
International Journal of Child, Youth and Family Studies (2014) 5(2): 308-331

The majority of interviews were conducted in women's homes, while seven interviews took place at the ECE programs for the convenience of the participants. Families' homes were considered ideal spaces in which to conduct interviews as women felt most comfortable in their homes, and it provided opportunities to gain greater insight into each family's daily, lived experiences. The interviews began with lead questions related to women's immigration experiences, followed by probing questions to gather more detail. For example, in the part of the interview focused on immigration the first author asked, "Tell me about coming to the United States" then followed up with probes to learn more about the participants' experiences coming to the U.S. including: "Why did you come to the U.S. ?”; "What was the journey like?”; "Did you leave/join family or friends?”; "In general, how is life different here versus in your country of origin?” (Yoshikawa, Chaudry, Rivera, \& Torres, 2007).

All of the interviews were digitally audio-recorded. Interviews lasted for two to three hours, on average. All but one of the Latinas were interviewed in Spanish (one chose to be interviewed in English) with the assistance of undergraduate research assistants (UGRA) who were bilingual and bicultural. The UGRAs accompanied the first author to each interview with the Latinas and translated throughout the duration of the interview. Following each interview, the UGRA who assisted with the interview transcribed the interview into Spanish, and then translated it into English for analyses. The UGRAs randomly checked one another's transcriptions and translations for accuracy. All of the African women were interviewed in English due to limited resources for translators who spoke Amharic and/or Arabic. However, African mothers' comfort with and command of the English language, as a group, was stronger than the Latina mothers. In addition, the first author consistently repeated statements back to participants to ensure understanding and accuracy.

\section{Data Quality}

Trustworthiness of the data was ensured through the use of a variety of strategies as outlined by Guba (1981). Specific strategies were employed in this study to increase credibility, transferability, dependability, and confirmability - indicators of trustworthiness in qualitative research - including lengthy field experience and rich descriptions of these experiences, triangulation, and reflexivity (Krefting, 1999).

Nine months were spent in the field, in interaction with immigrant parents in ECE programs as well as their homes. This extended engagement in the field enabled the first author to become familiar and trusted among the participants, as well as to observe their experiences over this period of time. The first author used audio-recorded interviews to gather quotations from women regarding their ideas and experiences, which provided thick description necessary for trustworthiness in qualitative research. Specifically, utilizing the mothers' words offered direct evidence of participants' lived experiences, which adds to the credibility, transferability, and dependability of this study (Krefting, 1999). In addition, various methods of triangulation were employed to ensure data quality, and in turn, trustworthiness regarding the findings for this study. First, triangulation of data sources and methods was achieved by utilizing multiple data sources and methods, including field observations of parents, children, and staff, as well as conducting in-depth interviews with parents. Second, the authors employed triangulation of investigators. The UGRAs who assisted in translating the interviews with the parents also helped 
International Journal of Child, Youth and Family Studies (2014) 5(2): 308-331

interpret these interview and observation data from a cultural perspective. Third, all three authors coded the data, with each section being coded by two authors independently and then verified, which is explained in greater detail below. Together these varied methods of triangulation increased the credibility, dependability, and confirmability of this study and, in turn, helped to tell a more complete story about the experiences of these immigrant families. Finally, reflexivity (Krefting, 1999), or consideration of the researchers' backgrounds, was examined throughout this study in terms of how each author's experiences and perspectives contributed to data collection and analyses.

\section{Data Analyses}

Formal data analyses were divided into three phases: open coding, axial coding, and selective coding (LaRossa, 2005). During each phase of coding, two of the three authors coded all of the interviews. Transcribed interviews were loaded into Atlas.ti, a qualitative data management software program. During open coding, each interview was read and initially coded by all three authors using both sensitizing concepts (Van den Hoonard, 1997), as well as ideas that emerged from the data (LaRossa, 2005). The sensitizing concepts with which coding began were related to the authors' research questions regarding how women's families shaped their immigration experiences, including: reasons for migrating; journey from country of origin; adaptation to life in the U.S.; family of origin; gender roles; and social support. A constant comparison method was used throughout open coding, in which one to two sentence blocks of text were read and then compared with previous blocks of text to determine if the new block of text was an indicator of an existing category or if a new category needed to be created (Glaser \& Strauss, 1967). This aspect of the analyses yielded additional codes specific to immigration and family relationships, including: role of family in reasons for migrating; role of family in the immigration journey; and role of family in adjustment to life in the U.S.

During the second phase of analyses, axial coding, each of the salient categories or codes that emerged during open coding were examined by looking across cases to understand the various dimensions of each category (LaRossa, 2005). Next, all the pieces of text related to the most salient codes (e.g., role of family in reasons for migrating) were read to understand the various dimensions of each code. For example, what emerged from this phase of coding in relation to "the role of family in reasons for migrating" were the dynamics of the various ways families, particularly in terms of their needs for different kinds of support including economic, physical, and medical support, shaped women's decisions to migrate to the United States. Following open and axial coding, all three of the authors met and discussed the themes that emerged. When there was discrepancy among two of the authors, the third read the data and provided additional insight for moving forward in the coding process. Finally, the three authors worked together during selective coding to determine the main "story underlying the analysis" (LaRossa, 2005, p. 850), which ultimately reflected how family relationships shape women’s immigration experiences.

\section{Findings and Discussion}

Our findings outline three phases of women's migration processes, including various turning points and transitions related to migration as well as becoming a mother in the context of 
International Journal of Child, Youth and Family Studies (2014) 5(2): 308-331

immigration. We illustrate how these were shaped by the confluence of micro-level (women's experiences, family relationships) and macro-level (social, political, and historical contexts) factors. Women's immigration processes consisted of: pre-migration processes, migration journey to the U.S., and post-migration adjustment once in the U.S.

\section{Women's Pre-migration Processes}

The past several decades of migration research has acknowledged the need to examine women's pre-migration experiences and decisions to migrate, as opposed to earlier studies that viewed men as the sole actors in migration and women's roles as secondary (Curran et al., 2006). As noted, research has examined the push factors of the country of origin and the pull factors in the destination country that prompt individuals and families to migrate, and highlight the complexity of the pre-migration process (e.g., Alk et al., 2007). For women in this study, the premigration processes consisted of decisions to migrate, reasons for migrating to the U.S., and preparations for migration. These processes were shaped by their families, including their families of origin $(n=14)$, their families of procreation $(n=14)$, particularly their children either in their countries of origin or in the U.S., and for a few women, their future families of procreation $^{1}(n=4)$. In particular, for many women, the reasons they left their countries of origin and came to the U.S. were linked to the needs of their families in terms of their economic situations, emotional or physical support, and medical treatment needs, as reflected in the concept of linked lives (Elder, 1989; Greenfield \& Marks, 2006; Hutchinson, 2007).

Meeting the needs of family members within a given context influenced many women's pre-migration processes. In particular, some women $(n=14)$ indicated that they migrated to the U.S. because of economic needs. For 12 women, it was their partners' need for employment and limited opportunities for work in their country of origin that engendered the economic need. In some cases, the decisions to migrate were made by their male partners. This is a critical aspect of the pre-migration process, as prior scholarship has also suggested that for some women, the decision to migrate may reflect a power imbalance in which the male partner's economic needs and choices are prioritized (Killian et al., 2012; Meares, 2010). For a couple of women, economic reasons for coming to the U.S. were related to the needs of their families of origin. It is now well noted that women may serve as independent economic actors who migrate to further individual or family economic goals (Curran et al., 2006). In particular, when Esmeralda, a 21year-old Mexican woman, was 16 years old, her parents sent her and her siblings alone to the U.S. to earn money. Esmeralda had been working since the age of seven, when she had to quit school so she could pick vegetables to help support her family of origin. She described growing up in poverty, in a place where, "there isn't a single person who finishes secondary school or a person who has some type of diploma”. According to Esmeralda, her parents relied on her financial contributions due to her mother's illness, and thus they were unable to fully financially support Esmeralda’s younger sister. However, Esmeralda’s parents were emotionally distant, which continued after she migrated to the United States:

\footnotetext{
${ }^{1}$ We define families of origin as the families into which participants were born that include: parents, siblings, aunts, uncles, grandparents, and cousins. Families of procreation included participants' children and partners. Finally, in discussing their immigration stories, some women mentioned having considered their future families of procreation, or their future children to whom they had not yet given birth.
} 
International Journal of Child, Youth and Family Studies (2014) 5(2): 308-331

The only thing they want is for me to send them money, [nothing else], they never say anything, except if I don't call them. My mom is sick so she asks that I send money because we still have a younger sister [in Mexico]. But overall, they don't say much.

For some participants, their decisions to come to the U.S. were contingent on their families' needs for physical support. Samira’s decision to stay in the U.S. permanently, which was somewhat spontaneous, was contingent on the needs of her sister, Nyanath, who needed help with childcare while she finished her university degree in the U.S. Samira had been in school in Sudan working towards becoming a medical lab technician, but while visiting the U.S., Nyanath convinced her to stay and help her take care of her children.

Moreover, while migrating was a significant and life changing event, many women shared that their migration decisions were made quickly and were fairly spontaneous, with very little emotional or logistical preparation. This was particularly true among women who came from Mexico and Central or South America, many of whom did not have documentation. Elsa discussed her preparations to come to the U.S. from Mexico with her boyfriend who was migrating because he was unable to find employment in Mexico: "Honestly, since I never thought, 'Oh I'm going to go to the U.S.' I never thought about things... like, I'm going to have a lot of money...Didn't even think about having my kids here or anything....” Like Elsa, many Latinas left their countries of origin with limited planning and often to meet the needs of family. As such, their pre-migration preparation was often characterized by spontaneity instead of longterm planning. Women who came with visas - more common among African women who were better positioned to be awarded a visa through the diversity lottery - engaged in more planning than women without visas, but still reported limited forethought in their decisions to leave their countries of origin and come to the U.S.

While many women were quite spontaneous in their decisions to migrate, a small group of women $(n=7)$ described being more strategic and intentional about this decision. First, a couple of women came to support the medical treatment of family members. These women reported choosing to take personal action to come to the U.S. to meet the needs of a family member and while the action of coming to the U.S. was planned, their decisions to stay came after they were already in the country. These women helped their family members by earning money to send home for medical treatment or by finding better treatment for their family members in the U.S. The majority of women, and particularly those who sought medical treatment for themselves and/or family members in the U.S., indicated that public health care in their countries was inadequate and private medical care was too expensive. Isabel came to the U.S. to earn enough money to send back to her family in Mexico for her son's treatments for asthma. She described her reasons:

[My oldest son] was young and sick. He was born with bronchitis and he needed treatment. My brothers were already here so they told me I could come live with them here, work, and send money for [his treatment], because there was very little work in Mexico. 
International Journal of Child, Youth and Family Studies (2014) 5(2): 308-331

Ultimately, Isabel stayed longer than the three or four years she initially anticipated because her second daughter, who was born in the U.S., was diagnosed with leukemia at two years of age. Isabel stayed to seek medical treatment for her daughter. Marisol came to the U.S. to help her father who needed treatment for his diabetes. He had been sick for several years in Guatemala and her family could no longer afford his medications and treatments there, so he came to the U.S. for treatment. Two years later, Marisol joined him to help with his care after he went blind and lost his speech from the diabetes. These participants reflect the complex picture of women's migration in which they enact individual agency, but may be influenced or constrained by family needs (Glick, 2010; Settles, 2001) and the socio-political context in terms of ability or lack of ability to access certain types of health care (Killian et al., 2012).

In sum, the majority ( $n=32)$ of women's decisions to migrate to the U.S. were contingent on family members - illustrating the idea of linked lives - with about one-third of these women coming to the U.S. because of an intimate couple relationship. Other women's decisions to come to the U.S. were influenced by the needs of their families of procreation and families of origin, particularly in terms of physical, emotional, and medical support. A small group of women discussed deciding to come to the U.S. so their future families of procreation would be well supported. These findings reflect Settles' (2001) and Glick’s (2010) arguments that decisions regarding migration are not solely individual decisions but that they are shaped by families as well as social networks, and often set in motion by macro-level forces that are interpreted by the family (Settles, 2001). However, our findings add an additional layer of complexity in relation to the timing of decisions to migrate. In particular, women exhibited varying levels of spontaneity or strategic thinking regarding migration decisions, which were shaped by family need, socio-political contexts, and documentation status. Understanding this additional component of women's decision to migrate can inform how family practitioners work with immigrant families. While migration is a significant and life-changing decision for both individuals and families, women in this study frequently did not engage in long-term planning or preparation, which may mean that they faced additional challenges related to their migration processes, such as a lack of emotional preparation or resources to assist in the transition to becoming settled in the U.S.

\section{Women's Journeys to the United States}

As discussed, the existing literature focused on immigrants' journeys across borders tends to focus on men from Latin America crossing into the United States (DeLuca et al., 2010; Infante et al., 2012). The limited studies on women's journeys and the gendered experience of migrating to a new country explore extreme aspects, including how and why women without documentation are more likely than their male counterparts to die during relocation due to either socio-political reasons (e.g., border protection) or factors of the physical environment (Pickering \& Cochrane, 2012). Documentation and the socio-political context were important aspects of the migration journey, which shaped important turning points in women's migration processes.

These experiences shed more light on the notion of linked lives or the role of family members in these journeys; over half of the participants $(n=28)$ reported that their families directly influenced their journeys to the U.S. 
International Journal of Child, Youth and Family Studies (2014) 5(2): 308-331

For women who migrated without documentation, which was the case for most women from Latin America $(n=14)$, this socio-political factor had a considerable impact on the women and their families. Women coming to the U.S. without documentation faced physically and emotionally grueling journeys. Some women traveled with members of their families of procreation, often a spouse, while other women traveled with members of their families of origin, including siblings, cousins, aunts, and uncles. Women who were undocumented, along with the family members with whom they traveled, experienced extremely difficult and expensive trips, as Sofia described:

It took almost a month. It was very hard. We all had to walk almost 11 days and by bus too. We would only sleep for, like, two hours and it was really hard. Through the desert when we were sleeping a snake bit me two times. My husband thought I was going to die.... It was \$6,000 per person...there were 10 of us who didn't have anything to eat, not even water...my feet would get very swollen because the shoes I wore were not my size and I would bleed a lot...I told my husband he should go on without me.

Some of the women who were undocumented directly experienced U.S. policy rooted in anti-immigrant sentiments (Vallas, Zimmerman, \& Davis, 2009), by being detained when they arrived in the U.S. (Infante et al., 2012; Wilson, 2000). This further exacerbated the distress of their relocation to the U.S., as Daniela describes:

They treat you - well, I think they treat dogs better than people...I was arrested for a month. Oh, I was crying because I felt when they arrested me I didn't know why they had to strip me. We were all a group of women in a room naked...I felt ridiculous...I didn't feel like I deserved that because I had not committed anything bad.... There were a lot of women and a man arrived and told us to take off all of our clothes. If you left the cell they had to strip search you when you returned. Since I did not want to be inspected, I would not go out [of the cell].

Daniela's story reflects what Infante and colleagues (2012) found among people crossing the Mexicali border in terms of being humiliated and psychologically mistreated. Ultimately, Daniela was released to her mother in the U.S. Daniela's migration experiences highlight a turning point (Hutchinson, 2007) faced by some women as they migrated. Experiences of detainment as well as other harsh conditions permanently shifted women's beliefs and cultivated a fear that some women carried with them into their new lives in the U.S. Daniela later experienced postpartum depression following the birth of her first child in the U.S. and described not wanting to leave her house, an experience which may have been exacerbated by the constant fear that plagued her in the U.S. due in part to her migration journey.

Women who arrived with documentation were spared from some of the fear that undocumented immigrants experienced; however, documented immigrants did face humiliation and psychological mistreatment rooted in the anti-immigrant policies and sentiments present in some communities, which restricted public benefits to immigrants for example. Aster's experiences with a local social service agency illustrate how immigrant women, regardless of documentation status, were sometimes mistreated. A single Ethiopian mother of three, Aster was 
International Journal of Child, Youth and Family Studies (2014) 5(2): 308-331

having problems paying her gas bill and sought assistance for this. The caseworker with whom she spoke asked her why she did not, "just ask [her] husband”. She described her experience:

They give me a hard time, and Medicaid and everything is in the same office. I don't want to be in that situation. Now they cut my Food Stamps, and I say, "forget it" - because [the caseworkers there] are very nasty people. Your dignity is [lost] and I don't want to be in that situation. I never been, never, never, never in my life on Food Stamps, this time.... If you are a foreigner they have to give you a hard time.

Women who had legal documentation, many of whom emigrated from Africa, generally came on visas or through family sponsorship. Despite the relative ease of their physical journey compared to the women without documentation, their travels were also influenced by the sociopolitical environment, as many left their countries due to civil unrest or war. For these documented women, the migration journeys were shaped primarily by the impact of having to separate from their families. For example, Maisa was living in a refugee camp in Sudan near the border with Chad because her family's village was burned in the civil war in Darfur. She traveled to Chad, applied for a U.S. visa there, and came on an airplane to the U.S. without her family. Although her relocation was not physically dangerous, it was a turning point in Maisa's life; Maisa began to feel considerable emotional pain related to worrying about her family's safety. Her migration experience also shaped her desire and ability to become a mother. She indicated that if she were still in Sudan she would not become a mother given the socio-political climate and not wanting to bring children into that context.

The notion of linked lives, coupled with the literature on civil unrest, war, and trauma (Newman \& Harris, n.d.), reflects the anxiety and worry these women felt as they fled their countries without their family members. As such, women with documentation who come from contexts where there is turmoil may also face difficulty being able to reunite with family, which increases their emotional hardship. Although this is not the same as being undocumented in terms of barriers to connect with family, there were still barriers, especially for women coming from war-torn countries or refugee camps.

For many women, family provided financial support for their journeys, providing monetary funds as well as connecting them with other resources. For African women, these resources often came in the form of family of origin or family of procreation sponsorship, which enabled them to travel to migrate to the U.S. legally, as well as travel in and out of the U.S., including returning home to visit their families. Particularly for the women from Africa, some had family members who were already in the U.S., and often served as visa sponsors. In turn, these women generally migrated to the location where their sponsors lived. Reflecting aspects of linked lives, individuals' decisions to migrate were often influenced by their families’ experiences and development. For example, Aster came because her mother was already living in Chicago and was able to sponsor her. It is possible that had Aster's mother never migrated, Aster would not have come to the U.S. either. Moreover, for women from Latin America, families often provided financial support to travel and settle in the U.S., especially families of origin. For example, Juliana's father used his house as collateral to finance her trip. Once in the U.S., Juliana needed to work to send money back to her father in Guatemala. When she did not 
International Journal of Child, Youth and Family Studies (2014) 5(2): 308-331

find opportunities where she had first settled, the need to repay the financial support from her family led her to continue her journey and relocate:

It was a good, stable place where we were living but I wasn't able to start paying the money I owed. So my dad...the money that he had borrowed on the house, he said they had given him three months to pay it back...and I wasn't working on this side [in the U.S.] so they were going to take away his house. [A friend] told me that in Washington [DC] there is more work... what mattered most to me was to pay my dad the money because he can't lose his house because what's the point of me being here if I can't help my family.... So [my friend] said, "well, come here and we'll find you a job”.

Some women initially made stopovers in other states because they had family that lived in different geographic areas or sought work there, before settling in one geographic area. The temporary nature of the initial arrangements and impending relocations complicated the migration process and added to their stress. Their transition did not end once they had arrived in the U.S., but financial strain and necessity, as well as the economic conditions in a particular location, sometimes led to an additional transition and an extension of the migration journey.

In sum, the majority $(n=28)$ of the women's journeys were contingent upon the financial, physical, and emotional supports of family members and shaped by socio-political factors in the U.S. There were notable differences between the experiences of women traveling with documentation and those without. In addition to the emotional hardship of separation experienced by most participants, women who were undocumented also experienced great physical hardship during their travels. As such, the socio-political environment and the policies that determine how and why individuals are granted legal access to the U.S. directly impacted women's physical and emotional well-being during migration and engendered a difficult and often harmful transition. Women also utilized the support of families to complete their travels, and, in some cases, to eventually arrive at a place where they hoped to be able to contribute to the economic needs of their families both in their home countries and in the U.S.; this reflects how families may support the migration of one member to achieve the family's overall goals, and marked a turning point for some women who began to take on a new role of family financial provider. Overall, these aspects of women's journeys were turning points that shaped their initial experiences of transitioning to life in the U.S.

\section{Motherhood as a Turning Point in Women's Adjustment to Life in the U.S.}

Migration to a new country is a significant life event, generally followed by a period of transition (Elder \& Kirkpatrick Johnson, 2003; Hutchinson, 2007; Jasso, 2003). However, most of the women in the study $(n=32)$ became mothers after arriving in the U.S., and as such, each experienced adjustment to life in a new country while becoming a mother. In many ways, becoming a mother in the U.S. was a turning point in their adjustment to life in a new country; having a child in the U.S. fundamentally and permanently changed the ecology of the women's lives (Hutchinson, 2007; Jasso, 2003), and marked a significant reason to stay in the U.S. Women described making active choices to stay in the U.S., which differed from the often spontaneous ways in which they described the processes that led to migration. Moreover, they remarked that their adjustment to the life in the U.S. seemed more pronounced and in some ways 
International Journal of Child, Youth and Family Studies (2014) 5(2): 308-331

more challenging after they became mothers, regardless of how long they had been in the U.S. Becoming a mother put additional and somewhat unexpected financial, logistical, and emotional strains on women that they had not experienced prior to becoming a parent in the U.S. This was especially true for mothers who came for economic opportunities. Esmeralda, a Mexican mother of one, described some of the financial challenges she faced after having children in the U.S.:

At the beginning everything was good because I earned good money and the rent was really cheap and I had money. We came because everything was better here. Then you start to have your own family and everything changes because now you have to worry about one more mouth to feed.

Esmeralda's experiences reflect current demographics that on average indicate high levels of poverty and economic hardship among immigrant families (Wight, Thampi, \& Chau, 2011). Multiple factors, such as economic status when entering the U.S. or barriers to accessing paid work, can influence the degree of financial hardship experienced by immigrant women and families; further, the transition to motherhood can also mark an increase in financial strain, as families facing economic barriers struggle to provide for children in contexts where they may not have the support of their families and communities, and where they may face anti-immigrant sentiments and policies.

However, despite the challenges related to access to resources as well as discrimination, motherhood appeared to offer a point of personal meaning, adding to women's sense of purpose and helping them persist through what were sometimes difficult circumstances. For instance, Maisa reported, “If I didn't have my kids, I wouldn't be happy”. In addition, some participants noted that even though it was difficult adjusting to motherhood in a new country due to lack of family support and resources, as well as different cultural beliefs regarding parenting, they believed that being in the United States was best for their children. Esmeralda discussed this when asked if she would prefer to be a mother in her country of origin:

In a way, yes, but in another, no, because you would have the same education that I had. What I mean is that if I would have stayed there I would have gotten married there and [my daughter] would have had the same luck that I had. Over there all the kids have the same luck.... It is better here than there.

It was salient for Esmeralda that she had made a choice that she believed was better for her children because the U.S. offered more opportunities for education and work. This facilitated her adjustment to life in the U.S. by offering a sense of greater purpose beyond herself - the wellbeing of her children.

Becoming a mother also shaped how women began planning for a future, which now included the possibility of remaining permanently. Elsa's discussion of her decision to stay in the U.S. illustrates how children often changed women's outlook regarding this decision:

Yeah, maybe I end up staying here for the rest of my life because of my kids. Or maybe I go back because personally I would like to be back with my family especially now that my parents are growing older and sicker... I prefer here because I am thinking about [my 
International Journal of Child, Youth and Family Studies (2014) 5(2): 308-331

children's] futures. When they are grown maybe they tell me they want to continue studying here. It's whatever they want to do. But if it was up to me, I'd [go back to] Mexico.

As noted, the views that women and their families held about better opportunities in the U.S. as compared to their countries of origin often played a part in the decision to migrate; as women became mothers in U.S., the focus shifted to opportunities specifically for their children, and engendered a transition towards wanting to stay permanently - a significant turning point and important aspect of their adjustment to life in a new country.

As women experienced becoming mothers in the U.S. and their planning and intentionality regarding remaining in the U.S. shifted, their families played varying roles in this process. Women's families of procreation played important roles in women's decisions to remain, and women's families of origin provided supports related to these decisions. Specifically, women's adjustment to life in the U.S. as mothers was influenced by families of origin ( $n=6)$, families of procreation $(n=15)$, or both their families of origin and families of procreation $(n=15)$. Further, this adjustment was shaped by women's abilities to access logistical and emotional support from individuals in the U.S., as well as their reasons for initially migrating. Individuals who provided women with the most support were often members of the women's families of origin, such as siblings, parents, or aunts and uncles. Sometimes these individuals were members of an extended family network through their partners (e.g., sister- or mother-in-law). In terms of logistical support, women noted that family members and family connections provided housing (both temporary and longer term), assisted with finding jobs, and helped with other important functions of daily living.

These supports were particularly salient for women with family living in the United States. The support provided by connecting with family members was a way to adjust to life as a mother in the U.S. by remaining a close family unit. Sofia stated:

My siblings, they are my close friends. There are four - three boys and one girl....We talk almost every day. Yes, at 8:00 a.m. they are already calling me. So we talk every day. ... Almost every day I talk to my sister.... Well, when we see each other we reunite and cook, talk about school, and what we did that week, and what our plans are for the future.

However, lack of family support in the U.S. was a challenge for many of the women, which is consistent with previous studies of immigrant parents with adolescent children (Perreira et al., 2006). For example, Amira had no family in the U.S. and her limited familial support appeared related to her feelings of loneliness and isolation, particularly as she faced the challenges of raising her children. In comparing her country of origin to the U.S., she reported, "That is different when you have a baby in my country, because here, no one, no one take[s] care of you. [It's] you, your husband, and kids only". As such, for some women, the experience of motherhood seemed to exacerbate the difficulties often faced by immigrants by accentuating their separation from family and support structures in their home countries. 
International Journal of Child, Youth and Family Studies (2014) 5(2): 308-331

Women voiced concerns related to their emotional adjustment after migrating. Even after having children in the U.S., women often felt alone and isolated, which appeared to be related to a lack of family support in the U.S. Alejandra described feeling alone while her husband worked long hours each day. "[Our first apartment] was too small. In El Salvador we had a house with a lot of land with animals. My parents always had animals...so, I felt like a prisoner. I spent my time crying and depressed, and with my little girl. My husband just worked". Some women compared the lack of support in the U.S. to the family support they would have received if they were in their country of origin, often from their families of origin. Women did remain in contact with their families in their countries of origin via telephone and the Internet, using prepaid phone cards as well as Skype.

Despite this connection with family members back home, they had to adjust to physical separation from family. Elsa described how she was reluctant to share her feelings with her mother in her country of origin: "No, I don't like to because [my mom] is already sad because I am here and I wouldn't want to depress her more [by] telling her that I am sad here". Sadness and nostalgia seemed to impact women differently based on their reasons for migrating. Women who came for economic reasons, and particularly those participants who were prompted to come by their partners and spouses and whose plans to remain in the U.S. emerged following the birth of a child in the U.S., seemed to have the most difficulties adjusting and remained most nostalgic for life in their countries of origin. Women with fewer difficulties adjusting were those who had family members living nearby, and women who felt they had agency in their decision to come and remain in the U.S.

In summary, women expressed how their adjustment to life in the United States tended to enter a more strategic, intentional phase following the birth of child, which was shaped by their families as well as the socio-political context of the U.S. After having children, women often made a conscious decision to stay permanently; prior to having children they had not made decisions about staying permanently. The importance of family and motherhood was evident, as many women reported continuing the difficult process of adjustment to the U.S. for the benefit of their children. When possible, women developed ways of remaining connected to their families and countries of origin to assist with their adjustment in the U.S., particularly following the birth of a child.

Given this, practitioners working with immigrant women may benefit from identifying how and in what ways motherhood impacts the immigrant adjustment experience. As women's views of permanency are likely to develop after becoming a mother, they may need assistance with transitioning to a long-term view of life in the U.S. Furthermore, understanding that motherhood may serve as both a source of purpose and a strain on immigrant women can help practitioners better serve this population. Finally, noting which factors might contribute to difficulty in adjustment (e.g., prior economic hardship) can enable practitioners to reach out to women who might be at risk and provide additional support and social services.

\section{Conclusion}

This study contributes to the understanding of first-generation immigrant women's immigration processes in a number of ways that have implications for both theory and practice. 
International Journal of Child, Youth and Family Studies (2014) 5(2): 308-331

First, the findings related to pre-migration processes indicate that while migration is a significant and life-changing event, for many women the decision to migrate is often made spontaneously or without extensive planning and preparation. As such, immigrant women may benefit from service providers offering assistance with short- and long-term planning, especially since women may now be physically separate from family systems that offered this support in the past. Of particular importance is to engage in planning assistance that attends to the complex considerations for immigrant women, including their roles within their families, cultural influences and expectations, and the socio-historical contexts in which they are situated. Given that both family needs and financial needs - which were often interrelated - figured prominently in many women's migration decisions, future research could explore the ways in which these factors intersect and interact to prompt migration. In particular, as economic situations change globally and women's economic opportunities continue to increase, studies can explore how socio-political factors (e.g., immigration or economic policies) impact women's decisions to migrate and prevent or hinder their access to opportunities.

During their migration journey, the status of women's documentation had a significant influence on their transition to the United States. While immigrant women generally faced financial stress and the emotional strain of separating from loved ones, undocumented women also faced physical hardship, detention, and abuse. Given the stressors noted during women's journeys to the U.S., especially for those who were undocumented, immigrant women and their families may be in need of services to address the impacts of stress and trauma. Service providers need to be aware of the complex journey process, how documentation impacts it, and how it may continue as women and their families make decisions to address economic needs even after they arrive in the U.S.

In working with immigrant women, identifying ways to bolster emotional support to buffer the impacts of separation and possible trauma during the relocation process can be an important aspect of both individual and family services. To better understand the impact of this turning point in women's lives, future research could further examine the impact of having multiple destinations, and ways in which service providers can serve this population so that any supports that are initiated at the original arrival point can be continued in subsequent locations. Further, as research continues to highlight the harsh and traumatic experiences of border crossing and detention, new policies and practices need to be explored and researched to prevent further harm to individuals and families.

Finally, a number of immigrant women in the study noted that entering the role of mother was a turning point in their adjustment to life in the U.S. Mothers recalled differences in terms of their expectations versus the reality of the new country, as well as the support available to them in the U.S. as compared to the assistance that they would have had in their countries of origin. As such, service providers working with immigrant mothers should assess the need for support, as this may be exacerbated among women with either limited family support in the U.S., or who are unable to access social services because of barriers such as documentation status. Assisting mothers in developing social support in the U.S. might be particularly salient for mothers experiencing isolation or feeling nostalgic for their countries of origin and families. 
Recent scholarship has noted that the use of electronic communication can provide a means for increasing connection between family members who are not in the same location (Bacigalupe \& Lambe, 2011); this could be particularly helpful for women who seek family support in decision-making and parenting as they transition to the role of mother. Opportunities to stay connected to their families and cultures of origin may also assist mothers in sharing their culture and traditions with their children, an important aspect of parenting for immigrant mothers. Additional research might compare the various factors that either hinder or help mothers in their adjustment process, as well as what interventions are most effective in assisting the diverse population of immigrant women in the U.S. Further, the impact of this process on men as they become fathers could also add to the understanding of immigrant families and help to better meet the needs of these families. 
International Journal of Child, Youth and Family Studies (2014) 5(2): 308-331

Table 1. Participant Characteristics (frequencies)

\begin{tabular}{|c|c|c|c|c|}
\hline & & $\begin{array}{c}\text { Total } \\
\text { women } \\
(N=40)\end{array}$ & $\begin{array}{l}\text { African } \\
\text { women } \\
(n=19)\end{array}$ & $\begin{array}{l}\text { Latina } \\
\text { women } \\
(n=21)\end{array}$ \\
\hline \multicolumn{5}{|l|}{ Participant age } \\
\hline & Mean age (in years) & 32.25 & 33.89 & 30.72 \\
\hline & $20-29$ & 15 & 5 & 10 \\
\hline & $30-39$ & 18 & 9 & 9 \\
\hline & $40-49$ & 7 & 5 & 2 \\
\hline \multicolumn{5}{|l|}{ Participant education } \\
\hline & less than high school & 11 & 4 & 7 \\
\hline & high school & 14 & 9 & 5 \\
\hline & some college & 13 & 5 & 8 \\
\hline & College & 2 & 1 & 1 \\
\hline \multicolumn{5}{|l|}{ Poverty Status } \\
\hline & Income below FPL & 40 & 19 & 21 \\
\hline \multicolumn{5}{|l|}{ Participant employment } \\
\hline & $\begin{array}{l}\text { Full time employment } \\
\text { Part time employment }\end{array}$ & $\begin{array}{r}22 \\
8\end{array}$ & 4 & $\begin{array}{r}15 \\
4\end{array}$ \\
\hline & Not employed & 10 & 8 & 2 \\
\hline \multicolumn{5}{|c|}{$\begin{array}{l}\text { Documentation upon Arrival in } \\
\text { U.S. }\end{array}$} \\
\hline & $\begin{array}{l}\text { Documented- family } \\
\text { reunification }\end{array}$ & 14 & 8 & 6 \\
\hline & Documented- diversity lottery & 6 & 6 & 0 \\
\hline & Documented- refugee & 3 & 3 & 0 \\
\hline & Documented- work visa & 2 & 2 & 0 \\
\hline & Undocumented & 15 & 0 & $15^{1}$ \\
\hline \multicolumn{5}{|l|}{ Time in U.S. } \\
\hline & Avg. years & 9.08 & 9.57 & 8.62 \\
\hline \multirow{4}{*}{$\begin{array}{l}\text { SES in Country of Origin } \\
(C O O)\end{array}$} & Range in years (min-max) & $2-21$ & $2-20$ & $5-21$ \\
\hline & Higher in $\mathrm{COO}$ than in U.S. & 10 & 5 & 5 \\
\hline & Same in $\mathrm{COO}$ and U.S. & 12 & 8 & 4 \\
\hline & Lower in COO than in U.S. & 16 & 5 & 11 \\
\hline \multicolumn{5}{|l|}{ Couple relationship } \\
\hline & Married/ Cohabiting & 31 & 15 & 16 \\
\hline & Single & 9 & 4 & 5 \\
\hline
\end{tabular}

${ }^{1}$ Three women did not explicitly state whether or not they were documented. However their journeys to the U.S. in terms of crossing borders with coyotes indicate they likely came to the U.S. without legal documentation. 
International Journal of Child, Youth and Family Studies (2014) 5(2): 308-331

\section{References}

Alk, E. A., Maroun, N., Major, S., Afif, C., Chahoud, B., Choucair, J., ... Schunemann, H. J. (2007). Why are you draining your brain? Factors underlying decisions of graduating Lebanese medical students to migrate. Social Science \& Medicine, 64(6), 1278-1284. doi: 10.1016/j.socscimed.2006.10.021

Bacigalupe, G., \& Lambe, S. (2011). Virtualizing intimacy: Information communication technologies and transnational families in therapy. Family Process, 50(1), 12-26. http://dx.doi.org/10.1111/j.1545-5300.2010.01343.x

Bankston, C. L., \& Zhou, M. (2002). Social capital and immigrant children's achievement. In B. Fuller \& E. Hannum (Eds.), Schooling and social capital in diverse cultures (Vol. 13, pp. 13-40). Boston: JAI. http://dx.doi.org/10.1108/s1479-3539(2002)0000013002

Bashi, V. F. (2007). Survival of the knitted. Stanford, CA: Stanford University Press.

Britz, E., \& Batalova, J. (2013). U.S. in focus: Frequently requested statistics on immigrants and immigration. Washington, DC: Migration Policy Institute. Retrieved from http://www.migrationinformation.org/usfocus/display.cfm?ID=931

Carter, B., \& McGoldrick, M. (2005). The expanded family life cycle: Individual, family, and social perspectives (3rd ed.). Boston: Allyn \& Bacon.

Cerrutti, M., \& Massey, D. S. (2001). On the auspices of female migration from Mexico to the United States. Demography, 38(2), 187-200. http://dx.doi.org/10.1353/dem.2001.0013

Chen, S. X., Benet-Martinez, V., \& Bond, M. H. (2008). Bicultural identity, bilingualism, and psychological adjustment in multicultural societies: Immigration-based and globalizationbased acculturation. Journal of Personality, 76(4), 803-837. doi: 10.1111/j.14676494.2008.00505.x

Curran, S. T., Shafer, S., Donato, K. M., \& Garip, F. (2006). Mapping gender and migration in sociological scholarship: Is it segregation or integration? International Migration Review, 40(1), 199-223. doi: 10.1111/j.1747-7379.2006.00008.x

Daly, K. J. (2007). Qualitative methods for family studies and human development. Los Angeles, CA: Sage.

DeLuca, L. A., McEwen, M. M., \& Keim, S. M. (2010). United States-Mexico border crossing: Experiences and risk perceptions of undocumented male immigrants. Journal of Immigrant Minority Health, 12(1), 113-123. http:/dx.doi.org/10.1007/s10903-008-9197-4

Dominguez, S., \& Lubitow, A. (2008). Transnational ties, poverty, and identity: Latin American immigrant women in public housing. Family Relations, 57(4), 419-430. 
International Journal of Child, Youth and Family Studies (2014) 5(2): 308-331

Elder, G. H. (1989). The life course as developmental theory. Child Development, 69, 1-12. http://dx.doi.org/10.1111/j.1467-8624.1998.tb06128.x

Elder, G. H., \& Kirkpatrick Johnson, M. (2003). The life course and aging: Challenges, lessons and new directions. In R. Settersten (Ed.), Invitation to the life course: Toward a new understanding of later life (pp. 49-81). Amityville, NY: Baywood.

Falicov, C. J. (2007). Working with transnational immigrants: Expanding meanings of family, community, and culture. Family Process, 46(2), 157-171. http:/dx.doi.org/10.1111/j.1545-5300.2007.00201.x

Fitzpatrick, J. (1997). The gender dimension of U.S. immigration policy. Yale Journal of Law and Feminism, 9(23), 23-49.

Glaser, B., \& Strauss, A. L. (1967). The discovery of grounded theory: Strategies for qualitative research. Chicago, IL: Aldine Publishing Company.

Glick, J. E. (2010). Connecting complex processes: A decade of research on immigrant families. Journal of Marriage and Family, 72(3), 498-515. doi:10.1111/j.1741-3737.2010.00715.x

Goldin, I., Cameron, G., \& Balarajan, M. (2011). Exceptional people. Princeton, NJ: Princeton University Press.

Greenfield, E. A., \& Marks, N. F. (2006). Linked lives: Adult children's problems and their parents' psychological and relational well-being. Journal of Marriage and Family, 68(2), 442-454. http://dx.doi.org/10.1111/j.1741-3737.2006.00263.x

Guba, E. G. (1981). Criteria for assessing the trustworthiness of naturalistic inquiries. Educational Resources for Information Center Annual Review Paper, 29(2), 75-91.

Henrici, J. (2013). Improving career opportunities for immigrant women in-home care workers. Washington, DC: Institute for Women’s Policy Research. Retrieved from www.iwpr.org

Hutchinson, E. D. (2007). A life course perspective. In E.D. Hutchinson (Ed.), Dimensions of human behavior: The changing life course (pp. 1-38). Thousand Oaks, CA: Sage.

Infante, C., Idrovo, A. J., Sanchez-Dominguez, M. S., Vinhas, S., \& Gonzalez-Vazquez, T. (2012). Violence committed against migrants in transit: Experiences on the northern Mexican border. Journal of Immigrant Minority Health, 14(3), 449-459. http://dx.doi.org/10.1007/s10903-011-9489-y

Isaac, S., \& Michael, W. B. (1981). Handbook in research and evaluation: A collection of principles, methods, and strategies useful in planning, design, and evaluation of studies in education and the behavioral sciences (2nd ed.). San Diego, CA: EDITS Publishers.

Jasso, G. (2003). Migration, human development, and the life course. In J. T. Mortimer \& M. Shanahan (Eds.), Handbook of the life course (pp. 331-364). New York: Kluwer. http://dx.doi.org/10.1007/978-0-306-48247-2_16 
International Journal of Child, Youth and Family Studies (2014) 5(2): 308-331

Kao, G., \& Rutherford, L. T. (2007). Does social capital still matter? Immigrant minority disadvantage in school-specific social capital and its effects on academic achievement. Sociological Perspectives, 50(1), 27-52. http://dx.doi.org/10.1525/sop.2007.50.1.27

Killian, C., Olmsted, J., \& Doyle, A. (2012). Motivated migrants: (Re)framing Arab women’s experiences. Women's Studies International Forum, 35(6), 432-446. doi: 10.1016/j.wsif.2012.09.006

Krefting, L. (1999). Rigor in qualitative research: The assessment of trustworthiness. In A. K. Milinki (Ed.), Cases in qualitative research (pp. 173-181). Los Angeles, CA: Pyrczak Publishers.

LaRossa, R. (2005). Grounded theory methods in qualitative family research. Journal of Marriage and Family, 67(4), 837-857. http:/dx.doi.org/10.1111/j.1741-3737.2005.00179.x

Meares, C. (2010). A fine balance: Women, work and skilled migration. Women's Studies International Forum, 33(5), 473-481.

McKether, W. L. (2008). Revealing social networks in qualitative data: An approach for increasing analytic firepower in qualitative data analysis. Journal of Ethnographic \& Qualitative Research, 2, 183-196.

Neufield, A., Harrison, M. J., Stewart, M. J., Hughes, K. D., \& Spitzer, D. (2002). Immigrant woman: Making connections to community resources for support in family caregiving. Qualitative Health Research, 12, 751-768. http://dx.doi.org/10.1177/104973230201200603

Newman, L., \& Harris, A. (n.d.). Refugees and asylum seekers: Supporting recovery from trauma. Retrieved from: http://tgn.anu.edu.au/sites/default/files/Refugee\%20Tipsheet.pdf

Ornelas, I. J., Perreira, K. M., Beeber, L., \& Maxwell, L. (2009). Challenges and strategies to maintaining emotional health. Journal of Family Issues, 30(11), 1556-1575. doi: 10.1177/0192513X09336651

Passel, J. S., \& Cohn, D. (2008). U.S. population projections: 2005-2050. Washington, DC: Pew Research Center. Retrieved from http://www.pewhispanic.org/files/reports/85.pdf

Patton, M. Q. (1990). Qualitative evaluation and research methods (2nd ed.). Newbury Park, CA: Sage.

Perreira, K. M., Chapman, M. V., \& Stein, G. L. (2006). Becoming an American parent. Journal of Family Issues, 27(10), 1383-1414. doi: 10.1177/0192513X06290041

Peters, J. F. (1999). Redefining Western families. Marriage \& Family Review, 28, 55-66. http://dx.doi.org/10.1300/j002v28n03_05

Pickering, S., \& Cochrane, B. (2012). Irregular border-crossing deaths and gender: Where, how, and why women die crossing borders. Theoretical Criminology, 17, 27-48.

http://dx.doi.org/10.1177/1362480612464510 
International Journal of Child, Youth and Family Studies (2014) 5(2): 308-331

Portes, A., \& Rumbaut, R. G. (2006). Immigrant America: A portrait. Berkeley, CA: University of California Press.

Senyurekli, A. R., \& Detzner, D. F. (2008). Intergenerational relationships in a transnational context: The case of Turkish families. Family Relations, 57(4), 457-467. http://dx.doi.org/10.1111/j.1741-3729.2008.00514.x

Settersten, R. (2003). Invitation to the life course: Toward a new understanding of later life. Amityville, NY: Baywood. http://dx.doi.org/10.2307/3089573

Settles, B. H. (2001). Being at home in a global society: A model for families’ mobility and immigration decisions. Journal of Comparative Family Studies, 32(4), 627-643.

Strauss, A., \& Corbin, J. (1990). Basics of qualitative research: Grounded theory procedures and techniques. London: Sage.

Treas, J. (2008). Transnational older adults and their families. Family Relations, 57(4), 468-478. http://dx.doi.org/10.1111/j.1741-3729.2008.00515.x

U.S. Census Bureau. (2013). International migration is projected to become primary driver of U.S. population growth for first time in nearly two centuries. Washington, DC: Author. Retrived from http://www.census.gov/newsroom/releases/archives/population/cb13-89.html

Vallas, S. P., Zimmerman, E., \& Davis, S. N. (2009). Enemies of the state? Testing three models of anti-immigrant sentiment. Research in Social Stratification and Mobility, 27(4), 201217. http://dx.doi.org/10.1016/j.rssm.2009.10.002

Van den Hoonard, W. (1997). Working with sensitizing concepts: Analytical field research. Thousand Oaks, CA: Sage.

Vesely, C. K. (2013). Low-income African and Latina immigrant mothers' selection of early childhood care and education (ECCE): Considering the complexity of cultural and structural influences. Early Childhood Research Quarterly, 28(3), 470-486. http://dx.doi.org/10.1016/j.ecresq.2013.02.001

Wight, V. R., Thampi, K., \& Chau, M. (2011). Poor children by parents’ nativity: What do we know? Retrieved from National Center for Children in Poverty website: http://www.nccp.org/publications/pdf/text 1006.pdf Wilson (2000)

Wilson, T. D. (2000). Anti-immigrant sentiment and the problem of reproduction/ maintenance in Mexican immigration to the United States. Critique of Anthropology, 20(2), 191-213. http://dx.doi.org/10.1177/0308275x0002000206

Yoshikawa, H. (2011). Immigrants raising citizens. New York: Russell Sage Foundation.

Yoshikawa, H., Chaudry, A., Rivera, A. C., \& Torres, K. (2007). Metrobaby Qualitative Study interview protocol (Unpublished document). Cambridge, MA: Harvard University. 